\title{
Tecnologia e informação em saúde: modelo de ensino-aprendizagem transdisciplinar
}

\author{
Maria Cristiane Barbosa Galvão
}

Professora da Universidade de São Paulo.

Ivan Luiz Marques Ricarte

Professor da Universidade de São Paulo.

Aline Priscila Daura

Egressa do Curso de Graduação Ciência da Informação e Documentação da Universidade de São Paulo.

Considerando conceitos básicos sobre tecnologia, informação e saúde; a observação de propostas curriculares; a análise de softwares e hardwares destinados ao campo da saúde, e a análise crítica da literatura, esta pesquisa focou-se na questão de como formar profissionais do campo da informação e do campo da informática que possam melhor solucionar as problemáticas relacionadas ao contexto da saúde. Para tanto, elaborou-se como hipótese inicial um modelo de ensino-aprendizagem transdisciplinar que abarca quatro aspectos: interação entre docentes e discentes de diferentes áreas; integração entre o contexto externo e o contexto da instituição educacional; condições institucionais; sistematização de um projeto de ensinoaprendizagem. Para analisar tal hipótese, adotou-se um método qualitativo, qual seja, a pesquisa-ação, durante $o$ período de ano, no qual foram ofertados dois cursos, com duração de 60 horas cada um e participação de 35 alunos. Como resultado da pesquisa, o modelo proposto se mostrou adequado para o ensino-aprendizagem em tecnologia e informação em saúde, sendo enfatizados parâmetros do contexto educacional transdisciplinar, como a competência linguística, a harmonizacao conceitual, os padrões éticos, a linguagem dos textos selecionados, e a relação entre as problemáticas discutidas no contexto externo e interno.

Palavras chave: Ensino, Informação, Tecnologia, Saúde, Transdisciplinaridade. 


\title{
Health information and technology: a transdisciplinary teaching and learning model
}

\begin{abstract}
The present research focused on the question of how professionals from the field of information and from the field of technology can be prepared to deal with healthrelated problems, taking into account the basic concepts of technology, information, and health; the observation of curricular proposals; the analysis of health-related software and hardware; and the critical analysis of current literature. As the initial hypothesis, a transdisciplinary teaching and learning model was proposed considering four aspects: interaction among lecturers and students from different fields of knowledge; integration between the external context with the context from the educational institution; institutional conditions; and systematization of a teaching and learning project. To analyze this hypothesis, a qualitative method, the action-research, was adopted during one year in the offer of two courses, with 60 hours each, and the participation of 35 students. The proposed model was adequate to teach and learn technology and information in health, and emphasized relevant parameters to be considered in transdisciplinary educational contexts, such as linguistic competence, conceptual harmonization, ethical standards, the language of selected texts, and the relation between problems discussed in the educational and external contexts.
\end{abstract}

Keywords: Teaching, Information, Technology, Health, Transdisciplinarity.

Recebido em 06.03.2011 Aceito em 12.12.2011

\section{Introdução}

O termo tecnologia da informação, sobretudo quando empregado pelos meios de comunicação de massa, muitas vezes é associado tanto à tecnologia propriamente dita como ao conteúdo semântico que ela suporta. Tal associação induz o público a pensar que problemas informacionais são meramente tecnológicos ou que, em havendo tecnologia da informação, a informação estará organizada e disponível para uso. Embora tal confusão não seja tão frequente no meio científico, neste artigo, faz-se uma clara distinção entre o termo tecnologia da 
informação e o termo informação, embora sejam complementares e interdependentes.

Associa-se, o termo informação a uma exposição em linguagem compreensível ao receptor/leitor/destinatário, como, por exemplo, o conteúdo apresentado em uma bula de medicamento. Já o termo tecnologia é associado aos meios que podem viabilizar a produção, a organização, a disseminação e o uso da informação, mas que não se confunde com ela. Por exemplo, o editor de texto que foi empregado na produção do conteúdo da referida bula. De forma complementar, entendese que existe um campo científico, relativamente delineado, focado na informação e denominado ciência da informação (TANG, 2004; IBEKWESANJUAN, 2010; PREBOR, 2010) e um campo científico focado na tecnologia da informação como é o caso da informática ou computação (DIETHELM, DÖRGE, 2010). Tais campos científicos se interagem de variadas maneiras a depender das culturas organizacionais e cognitivas de cada contexto (local, regional, nacional ou internacional), porém, há contextos onde esta integração é insipiente e contextos onde esta integração é imprescindível (DALRYMPLE, RODERER, 2007).

No que se refere ao termo saúde ele pode ser leigamente associado à ausência de doença ou enfermidades, mas este trabalho foca um conceito mais amplo de saúde, aceito nacionalmente e internacionalmente, e que está em sintonia com a Constituição da World Health Organization, ao afirmar que saudável é o estado de completo bem estar físico, mental e social (WORLD, 1946). A abrangência e complexidade da saúde enquanto campo científico, campo de assistência em saúde e campo de cultura demanda sistemas de informação refinados, rápidos, precisos, integrados tecnologicamente e informacionalmente, seja em decorrência dos muitos atores envolvidos no âmbito da saúde (população, gestores da saúde, equipe multiprofissional da saúde, pesquisadores e estudantes), seja pela cobertura de tais sistemas (local, regional, nacional e internacional), seja, por exemplo, pela necessidade de controle de endemias, epidemias e pandemias. Dessa forma, assume-se que a complexidade do campo da saúde (TULCHINSKY, VARAVIKOVA, 2009) no que se refere a sistemas de informação, demanda a integração de conhecimentos provenientes do campo da ciência da informação e do campo da informática.

Considerando os conceitos básicos anteriores; a observação de propostas curriculares interdisciplinares (envolvendo, geralmente, o campo da informática e o campo da saúde, ou o campo da informação e o campo da saúde, ou o campo da informática com o campo da informação), que possuem dificuldades em atingir seus objetivos, até mesmo pela exiguidade de docentes interessados e aptos em integrar tais cursos; a análise de alguns softwares e hardwares destinados ao campo da saúde, em geral muito custosos, mas que não promovem o benefício esperado dentro das instituições de saúde; bem como a análise crítica da literatura especializada que falha na proposição e avaliação de sistemas de informação em saúde, esta pesquisa focou-se nos seguintes problemas: como formar profissionais do campo da informação e do 
campo da informática que possam melhor solucionar as problemáticas relacionadas ao contexto da saúde? como promover a interação entre tecnologia e informação em saúde já no contexto de ensino-aprendizagem a fim de que as atividades, produtos e serviços desenvolvidos por estes futuros profissionais possuam qualidade e sigam requisitos compatíveis ao contexto da saúde?

Assumindo que a hipótese de pesquisa é uma resposta antecipada a um problema de pesquisa (POPPER, 1985; LOPES, 2001; CRESWELL, CLARK, 2007), para responder os questionamentos elencados, elaborouse como hipótese inicial um modelo de ensino-aprendizagem transdisciplinar, entendendo-se modelo enquanto um sistema idealizado e simplificado que, reunindo conceitos provenientes de uma ou várias teorias, propõe uma sistematização acerca de um objeto. Os modelos, tal como teorias e conceitos, tendem a ser provisórios na medida em que novos conhecimentos transformam os antigos, refutando-os ou reiterando-os. A hipótese, ou seja, o modelo proposto será detalhado na próxima parte deste artigo.

Para analisar tal hipótese adotou-se um método qualitativo de pesquisa, especificamente, a abordagem de pesquisa-ação que é caracterizada pelo processo cíclico envolvendo pesquisadores e profissionais atuando juntos em um ciclo particular de atividades, incluindo diagnóstico de problemas, intervenção ativa e aprendizagem reflexiva (AVISON et al., 1999). Na pesquisa-ação, o pesquisador exercita um modelo ou teoria juntamente com os profissionais em situações reais, obtém retorno a partir dessa experiência e modifica o modelo ou teoria com base nesse retorno, para que o novo modelo ou teoria possa ser novamente aplicado. Deve-se considerar, no entanto, que pesquisas empregando outras abordagens exclusivamente qualitativas ou quantitativas, ou mistas, poderão colaborar para refutação ou validação da hipótese proposta (CRESWELL, CLARK, 2007).

A análise do modelo e da hipótese compreendeu o período de ano, no qual foram ofertados dois cursos, com duração de 60 horas cada um, com uma participação efetiva total de 35 alunos.

\section{Proposição do modelo}

Em um texto clássico Gibbons (1998) alerta que as instituições de ensino superior, especialmente as universidades, são as instituições mais estáveis e resistentes a mudanças que já existiram nos últimos 500 anos. Baseadas no modelo de organização em campus, na interação face-a-face professor-aluno, em um específico formato de aula, elas se especializaram na transmissão do conhecimento de uma geração a outra. Sem mudanças na estrutura e no método, as universidades assumiram responsabilidades políticas, sociais, e tecnológicas. Assim, pergunta o autor, que mudanças seriam necessárias à universidade para atender as novas demandas sociais requeridas no século 21? O questionamento de Gibbons e de outros (COMISSAO, 1996) serve para ressaltar que as relações das ciências entre si e destas com a sociedade é um assunto que tem ocupado 
uma agenda de longa data, mas especialmente após os períodos das grandes guerras, se intensificando gradativamente no final do século passado.

A crítica que se faz ao modelo tradicional de universidade recai na sua restrita relação com a sociedade (contextos externos) e na sua organização em disciplinas relativamente isoladas. Embora as instituições educacionais de ensino superior cada vez mais ofereçam recursos informacionais, tecnológicos e interativos, 0 modo predominante de ensino-aprendizagem ainda traz traços de um especialista que compartilha, em sala de aula, seus conhecimentos com os aprendizes, como representado de forma esquemática na figura 1.

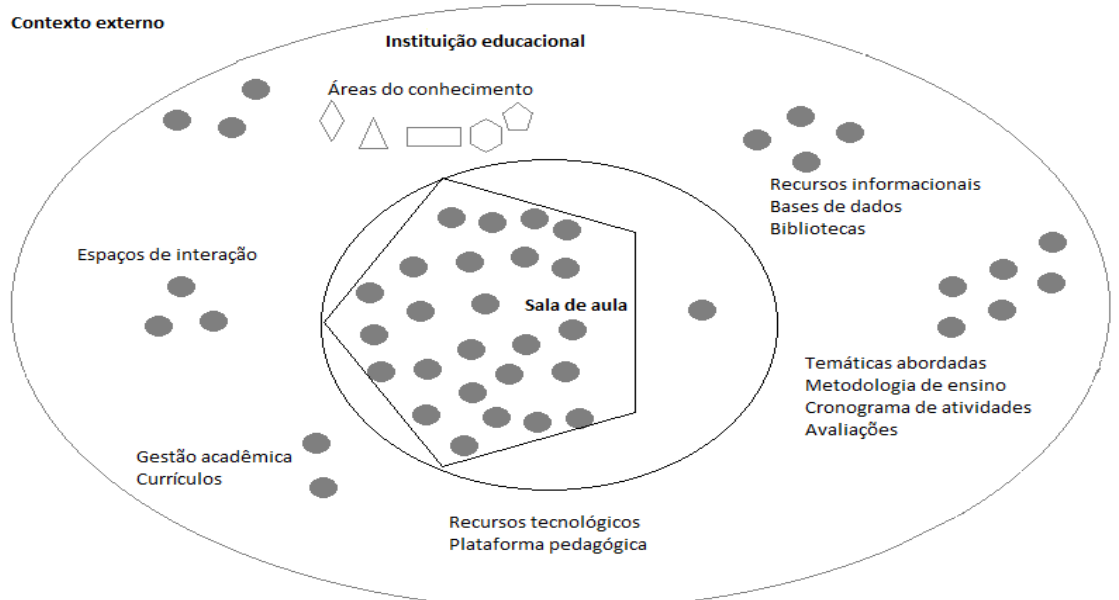

Figura 1 - Modelo de ensino-aprendizagem na abordagem tradicional

Como possibilidade para superação deste modelo de universidade, abordagens que transcendam os limites das disciplinas têm sido desenvolvidas por diferentes autores, dentre as quais a multidisciplinaridade, a metadisciplinaridade, a interdisciplinaridade e a transdisciplinaridade.

A multidisciplinaridade, também chamada de pluridisciplinaridade, consiste na justaposição de disciplinas, unidas em torno de um mesmo objeto, mas sem que haja intercâmbios conceituais ou metodológicos entre elas. Dessa forma, as barreiras disciplinares permanecem intactas e o trabalho realizado entre os professores e pesquisadores é complementar e de caráter colaborativo, somando diferentes ângulos de visão referentes ao objeto estudado. Assim, observa-se a natureza aditiva da multidisciplinaridade (ALMEIDA FILHO, 2005; ALVARENGA et al., 2005; NICOLESCU, 2005; ALVES, REINERT, 2007; SANTOS, 2007; HOLLAND, 2008; LUZ, 2009; DOMIK, FISCHER, 2010) quando, por exemplo, há um curso de graduação com a participação de docentes provenientes de diferentes áreas, cada um oferecendo sua visão sobre um tema comum mas que não trabalham conjuntamente para a transposição das barreiras disciplinares, tarefa esta que é delegada aos discentes.

Já a metadisciplinaridade se caracteriza pela presença de uma metadisciplina, integradora e situada em um nível epistemológico superior 
às demais disciplinas assegurando a interação e a interrelação entre elas (WERTH, 2003; ALMEIDA FILHO, 2005).

Por sua vez, a interdisciplinaridade constitui-se numa abordagem de uma problemática comum a um grupo de disciplinas que cria um meio de responder a questões complexas que não podem ser tratadas de forma satisfatória utilizando uma única abordagem disciplinar. Neste caso, há certa reciprocidade de intercâmbio entre elas, uma fecundação mútua, para estabelecer um novo nível de discurso e integração de conhecimento, o que leva ao mútuo enriquecimento e por vezes dá origem a novas disciplinas ou subdisciplinas com novos métodos de investigação e novas perspectivas teóricas (ALMEIDA FILHO, 2005; ALVARENGA et al., 2005; NICOLESCU, 2005; POMBO, 2006; SANTOS, 2007; AZEVEDO, ANDRADE, 2007; ALVES, REINERT, 2007; SANTOS, INFANTE-MALACHIAS, 2008; GODEMANN, 2008; LUZ, 2009; DOMIK, FISCHER, 2010).

A transdisciplinaridade consiste na integração de disciplinas com produção discursiva cooperativa entre os diferentes saberes, não somente entre o campo das ciências exatas e das ciências humanas, mas também da arte e da cultura. A abordagem transdisciplinar procura ir além das perspectivas disciplinares com a conceituação de novos objetos, métodos e concepções, apresentando um desafio epistemológico às abordagens anteriores; assim, a transdisciplinaridade não nega o disciplinar, mas o relativiza ao constituir-se num saber que organiza diferentes saberes e propõe a fusão entre a teoria e a prática, o filosófico e o científico, apresentando-se como um saber que é da ordem do complexo, englobando as diferentes disciplinas envolvidas no processo de pesquisa em um sistema que busca desconstruir limites rígidos entre elas em prol de soluções para problemáticas sociais (ALMEIDA FILHO, 2005; ALVARENGA et al., 2005; NICOLESCU, 2005; SANTOS, 2007; ALVES, REINERT, 2007; GODEMANN, 2008; LUZ, 2009; DOMIK, FISCHER, 2010).

Ressalta Gibbons (1998) que a transdisciplinaridade é composta pelo esforço consensual (entre várias disciplinas) para solução de problemas; por uma ênfase maior na relação entre teorias e práticas; pela intensificação dos canais de comunicação entre diversas instituições para produção e uso de conhecimento; bem como pela dinamicidade, sendo este modo de organização o mais compatível com a sociedade e as universidades do século XXI.

Pelo exposto, e considerando a complexidade informacional e tecnológica existente no contexto da saúde, que demanda uma necessária integração teórica e prática entre o campo da ciência da informação e da tecnologia com os problemas reais do campo da saúde, o modelo aqui proposto segue uma abordagem de ensino-aprendizagem transdisciplinar. $\mathrm{O}$ objetivo final deste modelo vai além do momento do ensino e da aprendizagem; volta-se para a construção da transdisciplinaridade, já no momento da formação, entre as áreas citadas e destas com as outras esferas da sociedade, aqui entendida como a população em geral, gestores da saúde, equipe multiprofissional, instituições de assistência, pesquisa e ensino em saúde. Desse modo busca-se, como defendido por Nicolescu (2005), a construção do conhecimento que transcende as fronteiras de cada 
disciplina e que levará à compreensão do mundo atual, não de forma antagônica, mas complementar ao conhecimento disciplinar.

De forma sintética, o modelo de ensino-aprendizagem transdisciplinar voltado para a tecnologia e informação em saúde é apresentado na figura 2 . Em relação ao modelo tradicional, apresentado na figura 1, destacam-se neste modelo três aspectos diferenciais. 0 primeiro é o convívio de docentes e discentes provenientes de diversas disciplinas no ambiente da sala de aula, e, em outros espaços. O segundo aspecto é a integração entre o contexto externo e o contexto da instituição educacional, por exemplo, por meio da relação com profissionais de outras instituições e da população, pela discussão de temáticas e problemas provenientes destes contextos, ou por outras formas de participação de docentes e discentes nesses contextos, como visitas, estágios, emprego, consultorias e voluntariado. O terceiro aspecto relaciona-se às condições institucionais, como a existência de flexibilização de currículos e da gestão acadêmica, de forma a permitir a integração das experiências transdisciplinares aos novos currículos, espaços de interação que garantam o convívio fora da sala de aula, os recursos tecnológicos (ferramentas de comunicação e plataformas pedagógicas) e informacionais (bibliotecas e bases de dados). O quarto aspecto reside na existência sistematizada e explicitada de um projeto transdisciplinar de ensino-aprendizagem que abarque as temáticas, as problemáticas e os referenciais a serem abordados, a metodologia de ensino, o cronograma de atividades, as formas de avaliação, e, as convenções comunicacionais. Cada um destes aspectos e de seus componentes será discutido a seguir, todavia, faz-se notar, que eles encontram-se fortemente relacionados, sendo interdependentes.

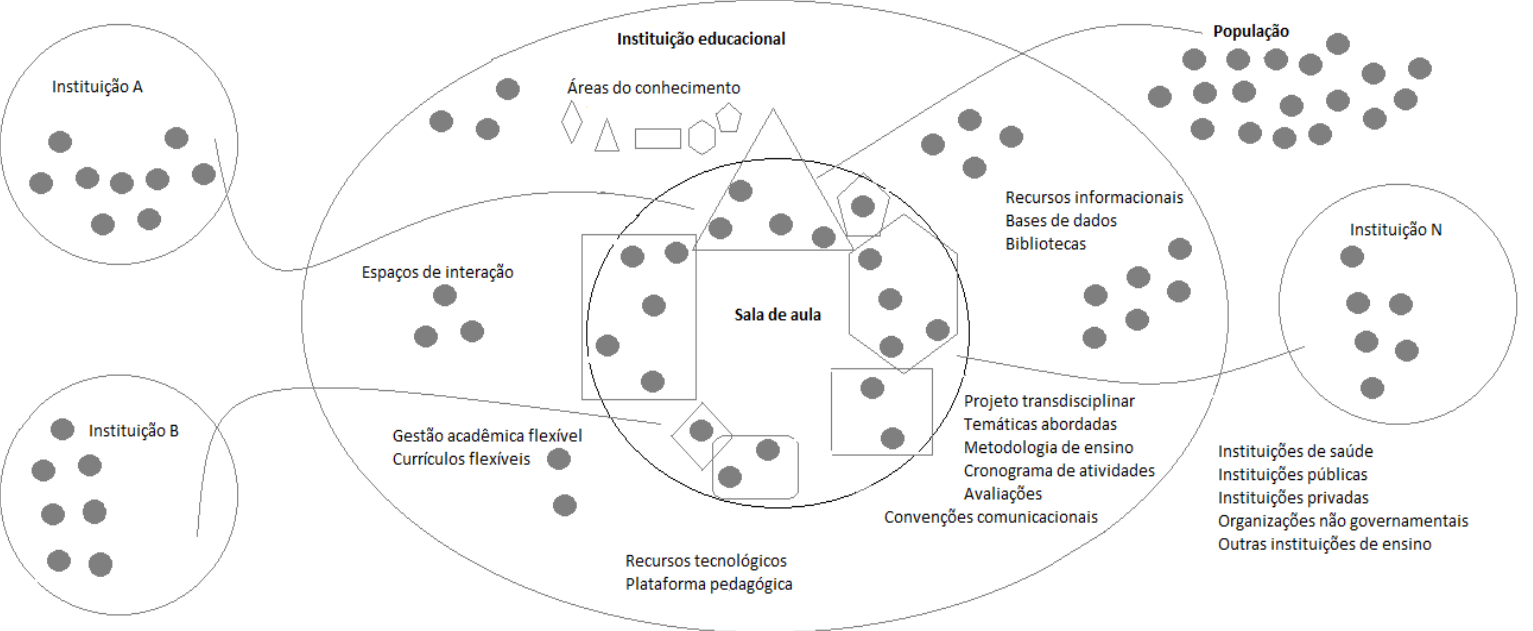

Figura 2 - Modelo de ensino-aprendizagem transdisciplinar para tecnologia e informação em saúde

Nas palavras de Fischer e Redmiles (2008), as competências transdisciplinares estão associadas ao conhecimento e habilidades necessárias para identificar e lidar com problemas científicos e práticos que cruzam as fronteiras disciplinares, problemas estes que são complexos, mal definidos, e demandam a comunicação e colaboração de 
pessoas de diferentes disciplinas e níveis educacionais. Assim, entende-se que para a concretização deste modelo um requisito essencial é a existência de um corpo docente composto por professores das diferentes áreas (neste caso, com formação no campo da informação, da informática e da saúde), ou seja, a construção de uma abordagem transdisciplinar requer diferentes visões (fundamentadas e relacionadas) sobre as problemáticas estudadas. Igualmente, tal diversidade deve ser considerada na constituição do corpo discente. Alunos provenientes de diferentes áreas em um mesmo ambiente podem observar mais concretamente as diversas visões de mundo, os conhecimentos convergentes ou divergentes que possuem, e serem sensibilizados para a importância e eventuais dificuldades do diálogo entre os diferentes atores.

$\mathrm{Na}$ abordagem transdisciplinar são também importantes os atores provenientes da sociedade, como os profissionais que atuam diretamente com problemáticas semelhantes às que serão estudadas no contexto de ensino-aprendizagem, e/ou membros da população afetada por tais problemáticas. As equipes transdisciplinares organizadas com membros oriundos do contexto das instituições de ensino e do contexto externo oferecem oportunidades únicas para colaboração, estabelecendo um caminho para traduzir a pesquisa em ação (DALE, NEWMAN, LING, 2010). Há que se garantir no contexto de ensino-aprendizagem a interação com estes atores oriundos do contexto externo. Assim, a proposta transdisciplinar requer uma abertura para o diálogo e para a relativização e análise crítica dos conhecimentos estabelecidos no contexto disciplinar.

Tal integração humana demanda, do contexto institucional, várias adequações como a garantia de que docentes e discentes com diferentes perfis e formações participem da iniciativa transdisciplinar, seja em sala de aula, seja no processo de planejamento, preparação e aperfeiçoamento do curso ou cursos a serem ministrados. Como ressalta Chevaillier (2002), as instituições de ensino superior precisarão se adequar às novas concepções de currículo, de pesquisa, de relacionamento com estudantes e com outras instituições de educação superior, tornando irrelevantes as fronteiras atualmente existentes entre provedores, setores educacionais e disciplinas. Logo, imagina-se ser inviável tentar uma abordagem transdisciplinar sem que os docentes envolvidos no processo tenham condições de trabalho compatíveis. De igual modo, a integração de discentes de diferentes áreas em um mesmo contexto demanda flexibilidade curricular e sistemas de gestão acadêmica compatíveis com esta flexibilidade. Recursos relacionados ao deslocamento dos discentes para a realização de visitas ou atividades extraaula, e, para a vinda de convidados e colaboradores externos devem ser considerados a fim de garantir uma relação com contextos reais de aprendizagem.

O planejamento do ensino-aprendizagem transdisciplinar demanda uma ampla discussão e negociação entre os docentes envolvidos para selecionar e definir o conteúdo programático a ser trabalhado. Não se trata, pois, de reunir conteúdos diversos e díspares sob a égide de um curso, mas de mapear temáticas que potencialmente tratem das problemáticas postas pela sociedade e que possam ser solucionadas pela 
comunhão de esforços. Harden (2000), que faz uma análise de onze possíveis abordagens de educação integrando diferentes áreas do conhecimento, coloca a educação transdisciplinar como o grau mais elevado e, portanto, mais elaborado, de uma possível integração. Especificamente, no caso da relação tecnologia e informação em saúde, algumas temáticas são de potencial interesse, como: conjunções e disjunções entre informática, informação e saúde; sistemas de saúde; atenção primária, secundária, terciária e quartenária em saúde; dados em saúde, informação em saúde, e conhecimentos em saúde; dimensão política e social de sistemas de informação em saúde; arquiteturas de sistemas de informação em saúde; interoperabilidade entre sistemas de informação em saúde; linguagens empregadas na saúde; documentos produzidos no contexto da saúde; prontuário eletrônico do paciente; organização, recuperação e acesso à informação em saúde; ética da informação em saúde; qualidade da informação em saúde; segurança da informação em saúde; preservação da informação em saúde; custos de sistemas de informação em saúde; avaliação de sistemas de informação em saúde; métodos de pesquisa científica relacionados à informática e à informação em saúde; gestão de sistemas de informação em saúde; sistemas de informação bibliográfica em saúde; sistemas de informação clínica; sistemas de informação epidemiológica; sistemas de informação para a gestão em saúde; eHealth e telemedicina; redes sociais e saúde; direito à informação em saúde, etc.

A discussão e problematização de qualquer temática acima relacionada requerem embasamento teórico. Motivo pelo qual se integra ao modelo proposto o acesso contínuo a bibliotecas, bases de dados nacionais e internacionais de qualidade, ou seja, que possuam impacto acadêmico e científico, a fim de que os envolvidos (docentes e discentes) na proposta transdisciplinar possam realizar a prospecção de informação atualizada ou retrospectiva, bem como compartilhar seus embasamentos teóricos com o grupo, ao longo de todo o processo de ensinoaprendizagem. Deste modo, espera-se que os discentes alcancem um grau de competência informacional (COBUS, 2008) que thes permita exercitar a prática transdisciplinar, não apenas ao longo do curso, mas também em sua carreira profissional. Esta condição é fundamental para que as discussões a serem realizadas caminhem dentro de um patamar acadêmico. $O$ acesso a esses recursos deve ser garantido institucionalmente.

O modelo proposto contempla ambientes reais e virtuais de integração entre docentes, entre docentes e discentes, e entre discentes e discentes. No caso específico dos docentes, estes precisarão estar em contato diário ou semanal, a depender das características do curso proposto, a fim de discutir o planejamento, o andamento, e o encerramento do curso e negociar sobre várias questões como métodos de ensino, avaliação contínua discente, dissolução de conflitos que possam vir a existir, bem como sobre os recursos pedagógicos adicionais demandados ao longo do curso. Tal forma de interação entre docentes é fundamental para que o curso ganhe em consistência e para que a 
atuação docente influencie positivamente os discentes em busca do diálogo, negociação e compartilhamento de conhecimentos. No que se refere à interação docente e discente, muito comumente, ela ocorre exclusivamente em sala de aula. Todavia, o presente modelo propõe que os docentes e discentes possam se comunicar fora da sala de aula. Para transformar esta proposta ideal em uma situação concreta, muitos recursos podem ser utilizados como plataformas tecnológicas educacionais e institucionais nas quais tanto o docente como o discente possam se comunicar sincrônica ou assincronicamente. Tais plataformas tecnológicas também podem ser empregadas na comunicação discente e discente, mas no caso destes devem ser previstos espaços adicionais de interação, para trabalho em grupo e intercâmbio de ideias. Pelo exposto, pode-se afirmar que o modelo proposto preconiza uma abordagem pedagógica híbrida, ou seja, com ambientes presenciais e virtuais de interação que maximizem o potencial comunicativo do grupo.

Deve-se considerar, no entanto, que plataformas tecnológicas para fins pedagógicos nem sempre são conhecidas e usadas por docentes e discentes, que devem, nas palavras de Ertmer (1999), vencer as barreiras tecnológicas de primeira (externas, institucionais) e de segunda (internas, pessoais) ordem. Em situações como esta, funcionários habilitados e designados pela instituição poderão oferecer treinamento para discentes e docentes, ou mesmo, prestar apoio técnico para o desenvolvimento do curso.

No que se refere aos métodos de ensino, estes devem privilegiar o diálogo e a pró-atividade dos discentes, pois a transdisciplinaridade é uma construção contínua e coletiva na qual a troca de informação é condição essencial (GODEMANN, 2008). Neste contexto são favorecidas as discussões em grupo, seminários, debates e entrevistas, em detrimento de abordagens que privilegiam principalmente aulas expositivas. Como observam Dale, Newman e Ling (2010), a construção de equipes transdisciplinares depende de muitas reuniões, pois muito esforço é investido em conectar as disciplinas, perspectivas, compartilhamento dos arcabouços intelectuais e mesmo no desenvolvimento da linguagem comum em torno das questões essenciais de pesquisa ou ensino que serão trabalhadas.

Considerando que o contexto de ensino-aprendizagem transdisciplinar requer a interação de pessoas de diferentes áreas, com costumes, perspectivas, crenças e linguagens distintas, algumas convenções comunicacionais, pautadas nos códigos de ética dos campos de conhecimento e das instituições envolvidas, devem ser estabelecidas para que o diálogo e o respeito à diversidade humana seja garantido. Tais convenções podem ser estabelecidas a priori pelos docentes ou serem negociadas conforme surjam situações conflitivas. Como bem observam Ho et al. (2008), o estabelecimento das interfaces entre contextos sociais e entre as práticas profissionais é um dos principais desafios da educação envolvendo profissionais de múltiplas áreas. 


\section{Analisando o modelo}

Para avaliar o modelo proposto de ensino-aprendizagem transdisciplinar, ofereceu-se um curso com 60 horas de duração tendo por público-alvo estudantes e profissionais das áreas de conhecimento ciência da informação e tecnologia da informação. O curso foi dirigido por dois docentes, um de cada área do conhecimento, que acompanharam conjuntamente todas as etapas envolvidas no seu planejamento e oferta, interagindo e colaborando continuamente de forma a garantir o desenvolvimento transdisciplinar dos temas, como recomendado por Domik e Fischer (2010). O título escolhido para denominar esse curso, Tecnologia e Informação em Saúde, procurou evidenciar a perspectiva adotada, na qual tecnologia e informação estão no mesmo nível de importância, diferenciando-se da conceituação mais usual do termo tecnologia da informação, no qual a existência de conteúdos informacionais fica apenas implícita e dependente dos conhecimentos cognitivos prévios da pessoa interpretante.

Duas instituições educacionais de ensino superior foram envolvidas na oferta do curso. Tal opção, decorrente da disponibilidade de cooperação entre os docentes dessas diferentes instituições, foi uma alternativa que se mostrou mais viável que estabelecer parcerias dentro de uma única instituição. No entanto, foi necessário que os docentes responsáveis assumissem a realização de ajustes locais, como a adequação do período de oferta das aulas.

Como bem observa Godemann (2008), a estrutura das universidades permanece altamente especializada e não é orientada para a cooperação e para o trabalho interinstitucional conjunto.

Para superar a distância geográfica entre as duas instituições, foram utilizados, além das salas de aula de cada instituição, recursos tecnológicos nelas existentes, como equipamentos de videoconferência para conexão dos grupos durante todas as aulas, conforme indicado na figura 3.

Além das atividades síncronas realizadas durante as aulas, o planejamento pedagógico para a disciplina considerou a necessidade de utilizar um ambiente de apoio para permitir a interação assíncrona entre docentes e discentes, bem como para manter os registros de atividades e a produção discente. Para tal fim, foi utilizada uma plataforma pedagógica com recursos para divulgação de agenda de atividades; disponibilização dos textos integrais adotados; formação de grupos; entrega de trabalhos discentes; e troca de mensagens por correio eletrônico.

Definidas a temática do curso e as instituições envolvidas, outro aspecto a destacar foi a seleção do público-alvo em cada instituição. Em ambas as instituições, o curso poderia ser oferecido em nível de graduação ou de pós-graduação. Alguns autores, como Domik e Fischer (2010), defendem que a transdisciplinaridade seja trabalhada apenas no nível de pós-graduação, quando os discentes teriam formação e maturidade para lidar com as questões transdisciplinares. Outros, como Rapport (1998), defendem que o momento de ensinar a 
transdisciplinaridade não depende da maturidade dos alunos e, na verdade, o pensamento transdisciplinar deve ser ensinado em todos os níveis educacionais. A opção dos docentes responsáveis foi de mesclar alunos dos últimos anos de graduação com alunos de pós-graduação, tendo como principal motivação o fato de que negar aos alunos de graduação o contato com o pensamento transdisciplinar pode significar formar profissionais pouco preparados para as situações que enfrentarão no mundo real. Assim, em uma instituição o curso foi oferecido primariamente a alunos de graduação do campo da informação, já nos últimos anos de formação, com a opção de participação de pósgraduandos, enquanto na outra instituição o curso foi oferecido na pósgraduação do campo da tecnologia, com opção de participação de alunos de graduação.

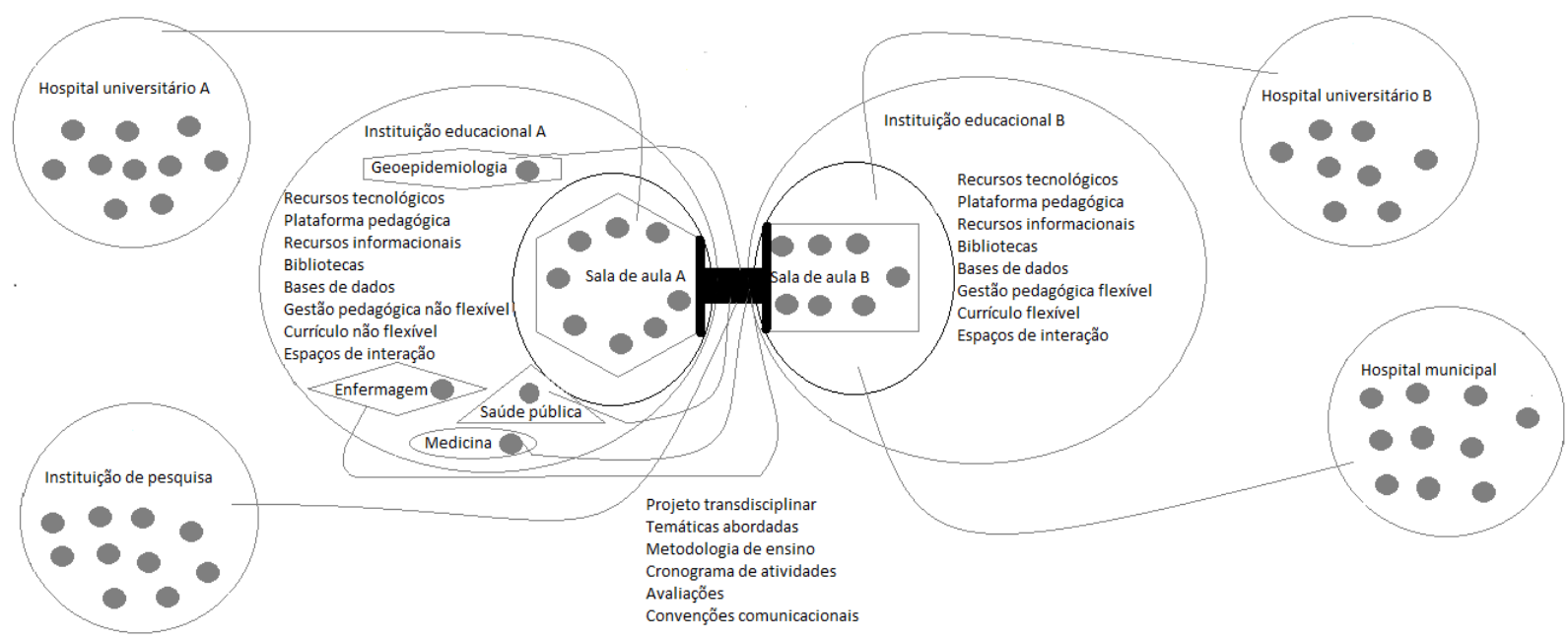

Figura 3 - Avaliação do modelo de ensino-aprendizagem transdisciplinar.

Em relação ao planejamento do curso, os docentes selecionaram, entre as temáticas de comum interesse, dez que pudessem ser trabalhadas pelos alunos no período de oferta do curso, de quinze semanas. Neste caso, optou-se por cobrir um leque de temas suficiente para a promoção do diálogo, e do ensino, aprendizagem e pesquisa transdisciplinar, embora cada tema pudesse ser objeto único de aprofundamento no curso, como ocorre - embora não com o mesmo caráter transdisciplinar da presente proposta - em outras instituições (UNIVERSITY, 2010). Tal abordagem pode ser caracterizada pelo termo 'primeiro em largura' (do inglês breadth-first), indicada por Domik e Fischer (2010) como adequada para iniciar estudantes na abordagem transdisciplinar.

Para cada tema selecionado, dois aspectos foram considerados pelos docentes no planejamento da disciplina. O primeiro consistiu no levantamento de questões reais associadas a cada tema, questões essas derivadas da vivência dos próprios docentes em projetos na área e da interação com outros profissionais, ligados às instituições educacionais ou externas. O segundo aspecto consistiu na revisão da literatura para a 
definição da bibliografia a ser empregada como base para discutir essas questões e para o estabelecimento do diálogo, considerando fontes de informação relevantes das três áreas envolvidas (informação, informática e saúde). Considerando a experiência do docente em cada área, partiu-se para a busca de um consenso em relação às abordagens que seriam favorecidas em cada tema e dos textos que seriam empregados. Houve negociação a fim de selecionar textos que pudessem ser inteligíveis aos discentes das duas áreas do conhecimento, sem perder a qualidade e a pertinência associadas aos objetivos propostos. Para alguns temas foi possível adotar um único texto base, a partir do qual as diferentes visões seriam trabalhadas. Em outros, adotou-se mais de um referencial teórico de base de modo a contemplar as linguagens de cada área. Como bem destacam Pereira e Funtowicz (2006), o exercício da transdisciplinaridade requer mais que o simples reconhecimento de diferentes perspectivas; ele requer uma harmonização de linguagens e uma contextualização social, cultural e política. O quadro 1 apresenta os temas, textos bases adotados e exemplos de problemas que foram trabalhados em cada tema. 
Tecnologia e informação em saúde : modelo de ensinoaprendizagem transdisciplinar
Maria Cristiane Barbosa Galvão; Ivan Luiz Marque Ricarte; Aline Priscila Daura

\section{Quadro 1 - Temas, textos base e exemplos de problemas}

\begin{tabular}{|c|c|c|}
\hline Temas & Textos base & Exemplos de problemas relacionados \\
\hline $\begin{array}{l}\text { Congruência entre } \\
\text { informática e } \\
\text { informação na } \\
\text { saúde }\end{array}$ & $\begin{array}{l}\text { CHIASSON, M. et al. Expanding multi-disciplinary } \\
\text { approaches to healthcare information technologies: what } \\
\text { does information systems offer medical informatics? Int J } \\
\text { Med Inform, 76(Suppl.1):S89-97, } 2007\end{array}$ & $\begin{array}{l}\text { Nas instituições de saúde quais são as competências a serem } \\
\text { assumidas pelos profissionais da informação e da } \\
\text { informática? Como elas se diferenciam e se complementam? }\end{array}$ \\
\hline $\begin{array}{l}\text { Conceitos de dados, } \\
\text { informação e } \\
\text { conhecimento em } \\
\text { saúde }\end{array}$ & $\begin{array}{l}\text { CHEUNG, K. et al. HCLS 2.0/3.0: Health care and life } \\
\text { sciences data mashup using Web 2.0/3.0. J Biomed Info, } \\
\text { 41(5):694-705, } 2008 \\
\text { ZINS, C. Conceptual approaches for defining data, } \\
\text { information, and knowledge. J Am Soc Inform Sc, } \\
\text { 58(4):479-93, } 2007\end{array}$ & $\begin{array}{l}\text { Há, nas instituições de saúde, uma confusão e dispersão } \\
\text { generalizada entre a produção de dados, informação e } \\
\text { conhecimento em saúde, com impacto para a qualidade dos } \\
\text { sistemas de informação em saúde, propriamente ditos, para a } \\
\text { assistência em saúde, para a pesquisa e gestão em saúde. }\end{array}$ \\
\hline $\begin{array}{l}\text { Arquiteturas de } \\
\text { sistemas de } \\
\text { informação em } \\
\text { saúde }\end{array}$ & $\begin{array}{l}\text { HAUX, R. Health information systems: past, present, } \\
\text { future. Int J Med Inform, 7(3/4):268-81, } 2006\end{array}$ & $\begin{array}{l}\text { No contexto nacional e internacional, existe uma } \\
\text { multiplicidade de arquiteturas empregadas em sistemas de } \\
\text { informação em saúde. Quais são suas características e como } \\
\text { otimizá-las? }\end{array}$ \\
\hline $\begin{array}{l}\text { Linguagens de } \\
\text { especialidade em } \\
\text { saúde }\end{array}$ & $\begin{array}{l}\text { GARCÍA-JIMÉNEZ, A. Instrumentos de representación } \\
\text { del conocimiento: tesauros versus ontologías. An } \\
\text { Documentación, 7:79-95, } 2004 \\
\text { FREITAS, F.; SCHULZ, S.; MORAES, E. Pesquisa de } \\
\text { terminologias e ontologias atuais em biologia e medicina. } \\
\text { RECIIS, 3(1):8-20, } 2009\end{array}$ & $\begin{array}{l}\text { Nos países anglo-saxônicos ricos existem muitas } \\
\text { terminologias sistematizadas e atualizadas que podem e são } \\
\text { empregadas nos sistemas de informação em saúde. Como } \\
\text { atingir este patamar nos países de idiomas minoritários, nos } \\
\text { países subdesenvolvidos ou em desenvolvimento? }\end{array}$ \\
\hline $\begin{array}{l}\text { Estruturas de } \\
\text { documentos em } \\
\text { saúde }\end{array}$ & $\begin{array}{l}\text { HÄYRINEN, K.; SARANTO, K.; NYKÄNEN, P. } \\
\text { Definition, structure, content, use and impacts of } \\
\text { electronic health records: a review of the research } \\
\text { literature. Int J Med Inform, 77(5):291-304, } 2008\end{array}$ & $\begin{array}{l}\text { Muitos dos documentos produzidos nas instituições de } \\
\text { saúde são desconhecidos por alunos do campo da } \\
\text { informação e do campo da informática. Conhecer estes } \\
\text { documentos, seus conteúdos informacionais, suas estruturas } \\
\text { e suas funções comunicativas é um passo importante para o } \\
\text { planejamento de futuros sistemas de informação que } \\
\text { possuam alguma aderência dos usuários da informação. }\end{array}$ \\
\hline $\begin{array}{l}\text { Integração de } \\
\text { sistemas de } \\
\text { informação em } \\
\text { saúde }\end{array}$ & $\begin{array}{l}\text { EYSENBACH, G. Medicine 2.0: social networking, } \\
\text { collaboration, participation, apomediation, and openness. } \\
\text { J Med Int Res, 10(3):22, } 2008\end{array}$ & $\begin{array}{l}\text { Quais as metodologias existentes para viabilizar a } \\
\text { integração tecnológica e a interoperabilidade semântica dos } \\
\text { sistemas de informação em saúde? }\end{array}$ \\
\hline $\begin{array}{l}\text { Organização e } \\
\text { recuperação da } \\
\text { informação em } \\
\text { saúde }\end{array}$ & $\begin{array}{l}\text { PFEIFFER, K.; GÖBEL, G.; LEITNER, K. Demand for } \\
\text { intelligent search tools in medicine and health care. In } \\
\text { BLANKEN, H. et al. (Orgs): Intelligent Search on XML } \\
\text { Data, p.5-18. Heildelberg/Berlin:Springer, } 2003\end{array}$ & $\begin{array}{l}\text { Grande parte dos sistemas de informação em saúde não } \\
\text { contemplam modelos de recuperação da informação, ou } \\
\text { seja, são focados na entrada e não na saída de dados, ou no } \\
\text { uso da informação. Quais modelos de recuperação da } \\
\text { informação podem ser aplicados neste contexto? }\end{array}$ \\
\hline $\begin{array}{l}\text { Segurança da } \\
\text { informação em } \\
\text { saúde }\end{array}$ & $\begin{array}{l}\text { GRITZALIS, S. et al. Technical guidelines for enhancing } \\
\text { privacy and data protection in modern electronic medical } \\
\text { environments. IEEE Trans Inform Tech in Biomed, } \\
\text { 9(3):413-23, } 2005\end{array}$ & $\begin{array}{l}\text { Alguns sistemas de informação em saúde trazem } \\
\text { informações privadas que em se tornando públicas podem } \\
\text { causar vários danos pessoais, institucionais ou sociais. } \\
\text { Assim, quais são os modelos de segurança da informação } \\
\text { mais adequados para este contexto? }\end{array}$ \\
\hline $\begin{array}{l}\text { Preservação da } \\
\text { informação em } \\
\text { saúde }\end{array}$ & $\begin{array}{l}\text { CORN, M. Archiving the phenome: clinical records } \\
\text { deserve long-term preservation. J Am Med Inform } \\
\text { Assoc, 16(1):1-6, } 2009\end{array}$ & $\begin{array}{l}\text { A perda de informação de saúde pode causar prejuízos } \\
\text { pessoais, institucionais, políticos, sociais e científicos. Por } \\
\text { outro lado, hardware e software possuem vulnerabilidades. } \\
\text { Como propiciar uma preservação da informação em saúde } \\
\text { em curtos, médios e longos períodos? Que critérios } \\
\text { assistenciais, informacionais e tecnológicos devem ser } \\
\text { considerados? }\end{array}$ \\
\hline $\begin{array}{l}\text { Qualidade e custos } \\
\text { na implantação e } \\
\text { manutenção de } \\
\text { sistemas de } \\
\text { informação em } \\
\text { saúde }\end{array}$ & $\begin{array}{l}\text { JHA, A. K. et al. Use of electronic health records in U.S. } \\
\text { hospitals. New Eng J Med, 360(16):1628-38, } 2009 \\
\text { PATRICK, J. A Critical essay on the deployment of an } \\
\text { ED clinical information system: systemic failure or bad } \\
\text { luck? (Ensaio.) Universidade de Sydney, Austrália, } 2009 \\
\text { SILVA, F. G.; TAVARES-NETO, J. Avaliação dos } \\
\text { prontuários médicos de hospitais de ensino do Brasil. Rev } \\
\text { Bras Educ Med, 31(2):113-26, } 2007\end{array}$ & $\begin{array}{l}\text { Recursos aplicados em sistemas de informação em saúde } \\
\text { são retirados da aplicação direta na saúde. Assim, é preciso } \\
\text { pensar em soluções informacionais e tecnológicas viáveis e } \\
\text { funcionais para cada contexto. Algumas empresas propõem } \\
\text { soluções incompatíveis com os problemas existentes nas } \\
\text { instituições de saúde. Como agir dentro de uma ética } \\
\text { profissional, propondo soluções adequadas? Como avaliar } \\
\text { soluções e projetos de informatização no contexto da saúde? }\end{array}$ \\
\hline
\end{tabular}

O cronograma definido para o andamento do curso compreendeu duas semanas iniciais para adequação dos alunos ao modelo proposto; uma semana (em média) para a discussão de cada tema; avaliação contínua da disciplina e dos discentes; e um momento para o encerramento do curso. A dinâmica planejada para a discussão de cada tema foi: leitura prévia pelos discentes do texto ou textos indicados como base para o tema; apresentação do tema pelos docentes contemplando base teórica, esclarecimentos e discussões relativas ao texto base, bem como questões a serem trabalhadas pelos discentes para aprofundar a 
temática; trabalho realizado pelos discentes, conforme a indicação dos docentes em aula; apresentação pelos discentes dos resultados obtidos em suas pesquisas de aprofundamento, com discussão entre os pares; e análise dos resultados obtidos pelos discentes e fechamento do tema pelos docentes. Tal dinâmica foi elaborada para promover a busca pela informação de qualidade, pela interação e pela capacidade de comunicação com profissionais de outras áreas, competências consideradas essenciais no contexto transdisciplinar e para a atuação do profissional do século XXI.

Para que os discentes adquirissem as habilidades necessárias ao exercício transdisciplinar, o planejamento de atividades extraclasse foi organizado de forma a que eles as adquirissem gradualmente, à medida que os temas fossem trabalhados. Assim, nos primeiros temas os discentes fizeram, individualmente, o estudo de artigo indicado pelos docentes, enquanto que nos últimos temas os discentes realizaram, em grupos transdisciplinares, a pesquisa autônoma usando as bases de dados e fontes informacionais disponibilizadas pelas instituições. Em todas essas etapas, foi planejada a apresentação dos resultados aos pares, na forma escrita e verbal.

Concluída a programação para o desenvolvimento do curso, a próxima etapa foi sua divulgação aos potenciais interessados. Em uma instituição, essa divulgação foi realizada pelos meios convencionais de divulgação dos cursos de pós-graduação, pela sua inclusão na lista de cursos oferecidos na página web e em quadros de aviso da pósgraduação, sendo disponibilizadas vinte vagas. Na outra instituição, o curso foi divulgado pela lista de discussão dos alunos, sendo ofertadas, em caráter experimental, oito vagas para alunos ouvintes e que desejassem cursar a disciplina como atividade extracurricular.

A programação do curso também previu a participação de profissionais e docentes provenientes da área da saúde que aceitaram o convite para colaboração no curso. Dessa forma, além dos docentes responsáveis, participaram do curso de forma esporádica (para palestras e/ou entrevistas) ou contínua (acompanhamento das aulas pela Web) profissionais e docentes envolvidos com enfermagem, medicina, saúde pública, epidemiologia e gestão da saúde, alguns dos quais provenientes de hospitais universitários e instituições de pesquisa da área da saúde. Os docentes responsáveis também previram e incentivaram que os discentes visitassem instituições de saúde. Efetivamente, muitos deles se empenharam em concretizar este objetivo de forma voluntária, procurando a interação com clínicas especializadas, hospitais e outros profissionais da saúde, conforme representado na figura 3.

Finalizada a primeira oferta do curso, fez-se uma avaliação entre docentes e discentes, que culminou com o planejamento de uma segunda oferta do curso nos mesmos moldes. No entanto, considerando os conhecimentos prévios dos alunos, os docentes ajustaram a sequência de temas, incluindo uma discussão sobre o impacto do uso da informação por profissionais da saúde, com algumas atualizações na bibliografia de base. Um aluno doutorando da área de saúde, participante do programa de 
estágio docente, acompanhou todas as aulas presencialmente e os debates por meio da plataforma pedagógica, garantindo assim a interação contínua com um profissional da saúde. Além disso, nesta segunda oferta, incluiu-se este curso como atividade regular nas duas instituições.

Durante as duas ofertas do curso, os docentes responsáveis se reuniram semanalmente, antes e depois de cada aula, para definir as ações e avaliar os resultados alcançados. Como subsídio para definir e avaliar, os docentes consideraram as comunicações orais realizadas em sala de aula por todos os atores, assim como as comunicações registradas na plataforma pedagógica por meio de mensagens, fóruns de discussão e trabalhos realizados pelos discentes de forma individual ou coletiva e disponibilizados em seus respectivos portfólios.

\section{Resultados}

Conforme preconizado no método de pesquisa-ação, após cada ciclo de pesquisa é possível avaliar, de forma consciente e sistemática, os processos, as mudanças ou as atividades desenvolvidas. Conceitualmente, a abordagem transdisciplinar se mostrou adequada para o ensinoaprendizagem em tecnologia e informação em saúde. Embora, tal abordagem demande por recursos variados, nem sempre disponíveis em todas as instituições de ensino. Por outro lado, observa-se que há muitas instituições que não utilizam plenamente os recursos existentes por motivos de várias ordens, incluindo os das culturas historicamente estabelecidas, como assinala Gibbons (1998).

No que tange ao modelo proposto na figura 2, a estratégia para sua avaliação teve que considerar as especificidades institucionais, dentre as quais a insipiente cultura cooperativa, o modo de gestão acadêmica e o estado atual de currículos, ainda focados na disciplinaridade. Tais observações demandaram a criação de um modelo de avaliação específico, conforme apresentado na figura 3. Dessa forma, como solução para a interação transdisciplinar, duas instituições de ensino com competências diferenciadas trabalharam conjuntamente, além do apoio de outras instituições do campo da saúde. Tal cooperação se mostrou benéfica, pois as trocas de informação e conhecimentos foram intensas para todas as instituições e atores envolvidos.

Como resultado deste ciclo de pesquisa-ação, há que se destacar que o modelo de ensino-aprendizagem transdisciplinar não pode ser estático e seguir um fluxo de interação único e pré-determinado. Seu estabelecimento demanda assim flexibilidade em busca de soluções para sua implementação, conforme demonstrado por meio do modelo de avaliação.

Além das constatações anteriores, a implementação do modelo gerou transformações acadêmicas diversas. Dentre elas, destaca-se o estabelecimento de um diálogo contínuo entre os atores, no ambiente da sala de aula, por meio de videoconferência durante a aula e fora dos horários oficiais de aula, por meio de chats e correio eletrônico, a fim de discutir o andamento e os conteúdos do curso, bem como discutir e 
analisar criticamente projetos atuais em andamento e projetos para futura cooperação. Assim, estabeleceu-se um elo de transdisciplinaridade com continuidade.

Dentre os relatos dos discentes, os principais ganhos obtidos durante a avaliação do modelo, por meio da oferta de cursos, foram a superação de preconceitos entre as áreas, um incremento na facilidade de comunicação verbal e escrita, e uma conscientização coletiva da necessidade de se pensar os sistemas de informação em saúde de forma não disciplinar. Neste sentido, de uma relação e uma comunicação interpessoal inicial relativamente tímida, talvez calcada em estranhamento mútuo com traços de baixa-estima, houve um processo de inclusão no qual todos já se sentiam um pouco mais a vontade para expor seus conhecimentos e demandar esclarecimentos quando do surgimento de dúvidas sobre sua própria área ou das outras áreas. Igualmente, houve um incremento gradativo na realização de intervenções críticas e de discordância, mas que ao final buscavam por consensos que fossem adequados para ambas as áreas.

A participação de convidados provenientes das áreas de saúde foi positiva, com os discentes mostrando-se receptivos e manifestando suas visões por meio de perguntas ou observações. Tais participações foram extremamente relevantes na medida em que esclareceram aos discentes a necessidade da formação de equipes multiprofissionais para a solução dos problemas em saúde. No que se refere à forma de interação, ressalta-se que as participações de convidados que surtiram melhor impacto cognitivo foram realizadas por meio de entrevistas, já que pode-se canalizar a resolução de dúvidas que exigiam uma resposta transdisciplinar, e que dificilmente seriam contempladas por meio de uma palestra. Tal situação ratifica que os métodos de ensino a serem usados numa abordagem transdisciplinar devem potencializar as oportunidades de diálogo. Cabe observar que os convidados mostraram-se positivamente surpresos em relação à novidade da proposta e receptivos a novas colaborações.

Ainda na dimensão comunicacional, observou-se que a competência linguística, seja na língua materna, seja em língua estrangeira, é um fator de sucesso no contexto transdisciplinar, já que este exige de seus atores habilidade na compreensão, tradução e representação conceitual monolíngue e multilíngue. No caso específico da informação e tecnologia em saúde, os conhecimentos disponíveis estão dispersos em fontes informacionais e idiomas variados, como pode ser observado no conjunto de referências do quadro 1 . Por tal circunstância, observou-se que a capacitação linguística é um quesito essencial para o desenvolvimento transdisciplinar nas instituições de ensino.

Durante o ciclo de avaliação do modelo, a fim de estabelecer uma comunicação mais embasada, os docentes orientaram em vários momentos os discentes para que estes incrementassem suas competências informacionais, incluindo prospecção, seleção, análise critica e comunicação da informação para o grupo. Percebeu-se que embora sendo discentes do contexto da informação e da informática, poucos efetivamente tinham experiência em busca metodológica por informação técnica e científica. A 
fim de suprimir estas deficiências, foram realizadas algumas explanações sobre estratégias de busca e análise metodológica da informação. Com o andamento do curso, em ambas as ofertas, percebeu-se um incremento dos discentes na busca por referenciais teóricos que melhor embasassem suas formas de pensar. Assim, iniciou-se uma habilitação dos discentes para a educação e pesquisa contínua, calcada na competência informacional - requisito indispensável no âmbito da informação e tecnologia em saúde, já que estas áreas possuem substanciais atualizações diacrônicas.

No que tange as convenções comunicacionais, os docentes tiveram que harmonizar a terminologia empregada durante o curso para que todos os alunos pudessem compreender alguns conteúdos (verbais escritos e verbais orais). Esta harmonização foi fundamental para o desenvolvimento de algumas temáticas, sobretudo daquelas nos quais os textos base eram muito especializados. Dada a forte interação do grupo, foi necessário estabelecer um protocolo para o uso do microfone durante as aulas, para que todos tivessem a oportunidade de manifestar suas opiniões.

Os equipamentos utilizados para conexão das instituições durante as aulas foram de excelente qualidade, seguindo padrões internacionais de videoconferência, viabilizando boa interação em áudio e vídeo e funcionando dentro da normalidade. Eventuais problemas foram solucionados pela equipe técnica de apoio ou pelos docentes. Além dos equipamentos, destaca-se que a equipe técnica de apoio foi constituída, na primeira oferta, por quatro funcionários especializados em videoconferência, dos quais dois com pós-graduação. Na segunda oferta, o apoio dos funcionários foi flexibilizado já que os docentes envolvidos no processo conheciam os equipamentos disponíveis.

Em relação ao cronograma do curso, entende-se que o tempo de adaptação à proposta deva ser ampliado, já que se faz necessária uma transposição gradativa da cultura disciplinar para a cultura transdisciplinar. Este tempo poderá ser diminuído ou eliminado em contextos futuros, quando a cultura da transdisciplinaridade esteja mais enraizada nas instituições de ensino.

Em síntese, os resultados obtidos neste ciclo de pesquisa-ação reiteram o modelo proposto, bem como a necessidade de integração entre as áreas de tecnologia e informação em saúde, no contexto acadêmico e profissional, para maior benefício da sociedade. Embora exista um grande número de barreiras e culturas estabelecidas, incluindo as formas rígidas de avaliação do docente e do discente, possibilidades restritas para se avançar em carreiras não convencionais, e a pouca experiência em propostas transdisciplinares (FADEEVA, MOCHIZUKI, 2010), universidades podem ser propiciadoras da transdisciplinaridade. Para tanto, gestores, docentes e discentes devem ser preparados, estimulados e empenharemse para olhar além de suas próprias fronteiras, para a auto-reflexividade, para se envolverem em um processo de integração do conhecimento de forma crítica e para assumir novas posturas e idéias (GOODEMAN, 2008). Dessa forma, um requisito para o sucesso da transdisciplinaridade é que os participantes (gestores, docentes e discentes) estejam dispostos a se 
envolver em novos modos de pensar e agir, assumam uma atitude humilde para com a imensidão de conhecimentos e superem o sentimento de ameaça interior em relação ao ponto de vista do outro. A eficácia das relações é maior quando os participantes atuam como profissionais e tomadores de risco intelectual, confiam em seus próprios papéis e identidades profissionais, respeitam uns aos outros como iguais, e compartilham responsabilidades, conhecimento e autonomia com os demais (WALL, SHANKAR, 2008).

\section{Conclusão}

Este trabalho propôs e analisou, por meio de uma metodologia qualitativa, um modelo de ensino-aprendizagem transdisciplinar que se mostrou factível para o contexto de sua avaliação, ou seja, conclui-se o estudo validando-se a hipótese inicial. No entanto, entende-se que novas pesquisas em mesmo contexto e em contextos diferentes poderão incrementar o modelo proposto, delineando variáveis quantificáveis e comparáveis longitudinalmente.

Tal conclusão é reiterada por Creswell e Clark (2007) ao explicarem que o papel do pesquisador difere substancialmente na pesquisa qualitativa e na pesquisa quantitativa. Na pesquisa qualitativa, as reflexões, experiências e concepções do pesquisador estão na linha de frente guiando suas interpretações e considerações durante 0 desenvolvimento da pesquisa. Assim, o relato de pesquisa carrega, de forma muitas vezes explícita, os preconceitos e posicionamentos do pesquisador. Para garantir a acurácia do relatório de pesquisa qualitativa, as discussões podem ser retomadas com os sujeitos de pesquisa, com outros investigadores, com pares ou auditores externos a fim de que checar detalhes e rever todas as fases do estudo. Na pesquisa quantitativa, o pesquisador considera largamente os resultados de pesquisas anteriores e tenta estabelecer muitos estágios para reduzir os resultados inúteis derivados, por exemplo, de instrumentos de coleta de dados com palavras imparciais e susceptíveis de conduzir a certas respostas. Na modalidade de pesquisa quantitativa, a acurácia e a validade não estão relacionadas aos sujeitos de pesquisa, mas nas provas acumuladas que suportam a interpretação dos escores de teste para um objetivo específico. Tais provas abarcam a análise da estrutura interna de um teste, as análises teóricas e empíricas das respostas, a relação entre escores e variáveis externas, e a análise das consequências intencionais e não intencionais do teste usado. Dessa forma, a combinação de dados provenientes de pesquisas qualitativas e quantitativas fornece um panorama mais completo, abarcando, de um lado, mais fortemente as perspectivas dos sujeitos participantes e, de outro, o conhecimento já acumulado por gerações. Outras situações nas quais as abordagens qualitativa e quantitativa podem ser complementares ocorrem quando, por exemplo, desenvolve-se uma pesquisa qualitativa para explorar uma situação da qual se desconhecem variáveis, taxonomias, testes de 
aplicação ou escores. Assim, a pesquisa qualitativa pode ser um ponto de partida para estudos em larga escala (CRESWELL, CLARK, 2007).

Neste sentido, o presente trabalho trouxe contribuições importantes ao apontar parâmetros que precisam ser considerados no contexto educacional transdisciplinar, como a competência linguística, a harmonizacao de conceitos, o estabelecimento de padrões éticos comuns, a distância entre a linguagem dos textos adotados como base e a linguagem da área dos discentes e profissionais envolvidos, e a relação entre as questões discutidas na instituição de ensino com aquelas provenientes do contexto externo.

\section{Referências}

ALMEIDA FILHO, N. Transdisciplinaridade e o paradigma pós-disciplinar na saúde. Saúde e Sociedade, v.14, n.3, p.30-50, 2005.

ALVARENGA, A.T. et al. Congressos internacionais sobre transdisciplinaridade: reflexões sobre emergências e convergências de idéias e ideais na direção de uma nova ciência moderna. Saúde e Sociedade, v.14, n.3, p. 9-29, 2005.

ALVES, F.M.S.; REINERT, J.N. Percepção dos coordenadores dos cursos de graduação da UFSC sobre a multidisciplinaridade dos cursos que coordenam. Avaliação, v.12, n.4, p.685-702, 2007.

AVISON, D.E.; LAU, F.; MYERS, M.D.; NIELSEN, P.A. Action research. Communications of the ACM, v.42, n.1, p.94-97, 1999.

AZEVEDO, M.A.R.; ANDRADE, M.F.R. O conhecimento em sala de aula: a organização do ensino numa perspectiva interdisciplinar. Educar em Revista, n.30, p.235-250, 2007.

CHEVAILLIER, T. Higher education and its clients: Institutional responses to changes in demand and in environment. Higher Education, v.44, n.3, p.303-308, 2002.

COBUS, L. Integrating information literacy into the education of public health professionals: roles for librarians and the library. Journal of the Medical Library Association, v.96, n.1, p.28-33, 2008.

COMISSÃO Gulbenkian, Para abrir as ciências sociais. Cortez : São Paulo , 1996.

CRESWELL, J.W.; CLARK, V.L.P. Designing and conducting mixed methods research. Thousand Oaks: SAGE, 2007.

DALE, A.; NEWMAN, L.; LING, C. Facilitating transdisciplinary sustainable development research teams through online collaboration. International Journal of Sustainability in Higher Education, v.11, n.1, p.36-48, 2010.

DALRYMPLE, P.W.; RODERER, N.K. Library and information science and biomedical informatics: converging disciplines. Proceedings of the International Conference on Conceptions of Library and Information 
Science: Featuring the Future. Information Research, v.12, n.4, p.1-14, 2007.

DIETHELM, I.; DÖRGE, C. From context to competencies. Advances in Information and Communication Technology, v.324, p.67-77, 2010

DOMIK, G.; FISCHER, G. Coping with complex real-world problems: strategies for developing the competency of transdisciplinary collaboration. Advances in Information and Communication Technology, v.324, p.90-101, 2010.

ERTMER, P. Addressing first- and second-order barriers to change: strategies for technology integration. Educational Technology Research and Development, v.47, n.4, p.47-61, 1999.

FISCHER, G.; REDMILES, D. Transdisciplinary education and collaboration. Workshop on Education in $\mathrm{HCI}$; $\mathrm{HCI}$ in Education at the Human-Computer Interaction Conference, p.1-18, 2008. Disponível em: http://I3d.cs.colorado.edu/ gerhard/papers/hcic2008.pdf. Acesso em 28 fev. 2011.

GIBBONS, M. Higher education relevance in the 21st Century. Washington: World Bank, 1998.

GODEMANN, J. Knowledge integration: a key challenge for transdisciplinary cooperation. Environmental Education Research v.14, n.6, p.625-641, 2008.

HARDEN, R.M. The integration ladder: a tool for curriculum planning and evaluation. Medical education v.34, n.7, p.551-557, 2000.

$\mathrm{HO}$, K. et al. Making interprofessional education work: the strategic roles of the academy. Academic medicine: Journal of the Association of American Medical Colleges, v.83, n.10, p.934-940, 2008.

HOLLAND, G.A. Information science: an interdisciplinary effort? Journal of Documentation, v.64, n.1, p.7-23, 2008.

IBEKWE-SANJUAN, F. et al. Information science in Europe. Proceedings of the American Society for Information Science and Technology, v. 47, n.1, p.1-2, 2010.

LOPES, M.I.V. Pesquisa em comunicação: formulação de um modelo metodológico. São Paulo: Loyola, 2001.

LUZ, M.T. Complexidade do campo da Saúde Coletiva: multidisciplinaridade, interdisciplinaridade, e transdisciplinaridade de saberes e práticas - análise sócio-histórica de uma trajetória paradigmática. Saúde e sociedade, v.18, n.2, p.304-311, 2009.

NICOLESCU, B. Towards transdisciplinary education. The Journal of Transdisciplinary Research in Southern Africa, v.1, p.5-16, 2005.

PEREIRA, G.; FUNTOWICZ, S. Knowledge representation and mediation for transdisciplinary frameworks: tools to inform debates, dialogues \& 
deliberations. International Journal of Transdisciplinary Research, v.1, n.1, p.34-50, 2006.

POMBO, O. Práticas interdisciplinares. Sociologias, n.15, p.208-249, 2006. POPPER, K.L. A lógica da pesquisa cientifica. São Paulo, Cultrix, 1985.

PREBOR, G. Analysis of the interdisciplinary nature of library and information science. Journal of Librarianship and Information Science, v.42, n.4, p.256-267, 2010.

RAPPORT, D.J. Transdisciplinary education: where, when, how? Ecosystem Health, v.4, n.2, p.79-80, 1998.

SANTOS, S.; INFANTE-MALACHIAS, M.E. Interdisciplinaridade e resolução de problemas: algumas questões para quem forma futuros docentes de ciências. Educação e Sociedade, v.29, n.103, p.557-579, 2008.

SANTOS, M.S. Integração e diferença em encontros disciplinares. Revista Brasileira de Ciências Sociais, v.22, n.65, p.51-60, 2007.

TANG, R. Evolution of the interdisciplinary characteristics of information and library science', Proceedings of the American Society for Information Science and Technology, v.41, n.1, 2004, p. 54-63.

TULCHINSKY, T.H., VARAVIKOVA, E.A. The new public health. 2.ed. Burlington : Elsevier, 2009. 696p.

UNIVERSITY of Victoria. Health Information Science at the University of Victoria: Academic Programs. Disponível em http://hinf.uvic.ca/programs/index.php. Acesso em 25 fev 2011.

WERTH, A. Unity in diversity: the virtues of a metadisciplinary perspective in liberal arts education. Journal of the National Collegiate Honors CouncilOnline Archive, p.35-51, 2003.

WORLD Health Organization. Constitution. Conference held in New York from 19 June to 22 July 1946, signed on 22 July 1946 by the representatives of 61 States. Disponível em: http://www.who.int/governance/eb/constitution/en/index.html. Acesso em: 1 mar. 2011. 